\title{
Erratum to: What Design and Material Factors Impact the Wear and Corrosion Performance in Total Elbow Arthroplasties?
}

\author{
Mark P. Figgie MD, Timothy M. Wright PhD, \\ Denise Drinkwater BA, The Bioengineering Working Group
}

Published online: 6 August 2014

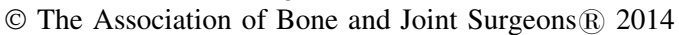

\section{Erratum to: Clin Orthop Relat Res DOI 10.1007/s11999-014-3781-9}

In the published study, "What Design and Material Factors Impact the Wear and Corrosion Performance in Total Elbow Arthroplasties?" the Bioengineering Working Group consisted of: Thomas D. Brown PhD, University of Iowa, Iowa City, IA, USA; Darryl D. D’Lima MD, PhD, Shiley Center for Orthopaedic Research and Education, La Jolla, CA, USA; A. Seth Greenwald, D.Phil (Oxon), Orthopaedic Research Laboratories, Cleveland, OH, USA;
Melinda K. Harman PhD, Clemson University, Clemson, SC, USA; Steven M. Kurtz, PhD, Exponent and Drexel University, Philadelphia, PA, USA; William M. Mihalko $\mathrm{MD}, \mathrm{PhD}$, Campbell Clinic Orthopedics and BME, Memphis, TN, USA; Orhun K. Muratoglu PhD, Massachusetts General Hospital, Boston, MA, USA; Clare M. Rimnac, PhD Case Western Reserve University, Cleveland, OH, USA; Markus A. Wimmer PhD, Rush University Medical Center, Chicago, IL.

The editors regret this error.

The online version of the original article can be found under doi:10.1007/s11999-014-3781-9. 